\title{
Diálogos socioambientais: a experiência do projeto Maria de Barro
}

\section{Socio-Environmental Dialogues: The Maria de Barro Project Experience}

\author{
Maria Teresa Franco RIBEIRO* \\ Vinicius Martins FERREIRA** \\ Rogério Rezende Martins FERREIRA***
}

\begin{abstract}
RESUMO
Os resultados pouco satisfatórios das políticas de desenvolvimento dos anos 1990 evidenciaram a necessidade de se refletir sobre os conceitos, práticas e interesses envolvidos nos projetos de desenvolvimento local. No contexto dessa reflexão, surgiram práticas inovadoras na perspectiva da preservação ambiental e da organização social. O projeto Maria de Barro, aqui discutido, é uma experiência que parte de um problema-chave do município de Nazareno: a degradação dos solos, que incorpora e dialoga com vários outros problemas do cotidiano da população, apontando a complexidade das transformações sociais e do sentido do desenvolvimento. Três conceitos orientaram o debate e o desenho das ações do projeto: desenvolvimento, territórios e tecnologias sociais.
\end{abstract}

Palavras-chave: desenvolvimento territorial; tecnologias sociais; voçorocas.

\begin{abstract}
The poor results from development policies in the 90 s highlighted the need to reflect on the concept, practice and interests involved in local development projects. In the context of this discussion emerged innovative practices from the perspective of environmental conservation and social organization. The Maria de Barro project that is discussed here is an experience from a key issue in the city of Nazareth. The degradation of soils merges and correlates to various other problems that these populations face in their daily life, indicating the complexity of social change and the sense of development. Three concepts have guided the discussion and design of this project: development, territory and social technologies.
\end{abstract}

Key-words: territory development; social technologies; gullies.

\footnotetext{
"Economista, Pós-doc no IHEAL, Paris III. Professora Associada III, Escola de Administração da Universidade Federal da Bahia. Email: mariatfr@uol.com.br "* Engenheiro Agrônomo, Mestre em Ciência dos Solos pela Universidade Federal de Lavras - UFLA. Instituto Voçoroca. Email: vinicius@projetomariadebarro.org.br

**** Engenheiro Agrônomo, Doutor pela Universidade Estadual de Londrina, Londrina, PR Instituto Voçoroca. Email: rogerio@projetomariadebarro.org.br
} 


\section{Introdução}

Alguns debates foram recorrentes na última década, como a questão da falência dos modelos de desenvolvimento impostos pelas agências internacionais para o desenvolvimento de países periféricos, o agravamento dos problemas ambientais e o aumento da exclusão social. $\mathrm{Na}$ perspectiva de aumentar a participação social, a partir dos anos 90 passa-se a privilegiar a dimensão local e estimular a incorporação de novos sujeitos políticos nos projetos de desenvolvimento. Agrega-se ao agravamento da questão ambiental o aumento da ação dos movimentos sociais e organizações contra-hegemônicas, como o Fórum Social, que estimulam a crítica aos modelos universais de desenvolvimento, a partir da valorização dos diversos tipos de saberes territorialmente constituídos. Trata-se de um movimento complexo e contraditório, como afirmam Dagnino e outros (2006), que assumirá forma e ritmo em cada país, determinados tanto pelas especificidades históricas locais, regionais e nacionais como pelas condições criadas pela globalização, agências internacionais e movimentos sociais alternativos. Tal movimento aponta os elos intrínsecos entre trajetórias de desenvolvimento, territorialidades e participação social. As trajetórias de desenvolvimento produzem e são produzidas pela história e as instituições territoriais.

Compreendendo a importância da história e os sentidos que ela pode imprimir em determinadas culturas, Sérgio Buarque de Holanda, em seu livro Raizes do Brasil, afirma:

A tentativa de implantação da cultura europeia em extenso território, dotado de condições naturais, se não adversas, largamente estranhas à sua tradição milenar, é, nas origens da sociedade brasileira, o fato dominante $\mathrm{e}$ mais rico em consequências. Trazendo de países distantes nossas formas de convívio, nossas instituições, nossas ideias, e timbrando em manter tudo isso em ambiente muitas vezes desfavorável e hostil, somos ainda hoje uns desterrados em nossa terra (HOLANDA, 1995, p. 31).

Comportamo-nos como conquistadores de passagem, em busca de riqueza. Forma essa de ver o mundo que pode ser também percebida nas práticas agrícolas aqui implantadas, como as queimadas, quando já existiam as "práticas de rotação dos cultivos ou o alqueive por homens que as devem conhecer da pátria de origem"1 e que mostra a atitude de esbanjamento diante da abundância de solos cultiváveis. O mesmo comportamento se reproduzirá no garimpo, onde o sentido de descobrir significava possuir, garimpar para partir. Nesses pequenos trechos da obra, Sérgio Buarque de Holanda nos mostra, no fundo, as bases em que foi constituída, nessa terra brasilis, a relação homem/natureza.

É essa relação que, fundamentalmente, vamos procurar compreender, a sua formação, potencialidades e desafios de transformação, tendo como pano de fundo uma experiência de desenvolvimento local realizada em Minas Gerais, no município de $\mathrm{Nazareno}^{2}$. Esse território, situado na região de Campos das Vertentes, na bacia do Alto Rio Grande, é marcado por intensa e grave presença de voçorocas ${ }^{3}$ na paisagem, indícios de um processo de desertificação originado pela mineração do ouro no século XVIII (PAULA, 2000). Assim, é a partir do grave problema das voçorocas, da dura paisagem "natural" com que convivem os moradores dessa comunidade, que se iniciam ações numa perspectiva transformadora que podem ser exemplificadas a partir do projeto Maria de Barro. A paisagem de Nazareno é a expressão dessa relação que o colonizador estabeleceu com o espaço, lugar de explorar, arrancar as riquezas e partir. Essa história e o sentido das relações estabelecidas com a natureza ajudam a explicar a realidade desse município e de outros com a mesma história. Por que esse nome?

\section{Maria: Mãe, Mãe Terra, organismo vivo e solidário, uma rede interdependente de relações, o papel das mulheres no desenvolvimento das comunidades. \\ Barro: Pai, Solo Sagrado, sistema fundamental para a vida, patrimônio universal, testemunho da história da humanidade.}

Nazareno é apenas um exemplo, entre vários, de uma trajetória de desenvolvimento inserida numa perspectiva colonialista e que definiu traços fundamentais da cultura e da sociabilidade brasileiras. A natureza é parte e resultado

\footnotetext{
${ }^{1}$ S. B. Holanda, Monções, 3 ed. Ampliada. São Paulo: Brasiliense, 1995. 26 ed. p. 163.

${ }^{2}$ Segundo José Heitor Guimarães, prefeito de Nazareno, o "Maria de Barro não surgiu por acaso em Nazareno. Lamentavelmente, somos um dos municípios mineiros cuja paisagem é mais marcada pelo dissabor das voçorocas. Contabilizamos 86 buracos (252 hectares) em uma área de apenas 3.300 hectares". In: FERREIRA; FERREIRA (Coords.). Maria de Barro tecendo a Rede Voçoroca. Nazarenos: Crides, 2009, 85 p.

${ }^{3}$ O termo voçoroca vem do tupi-guarani e significa terra rasgada (FERREIRA, V.; FERREIRA, R. Proteger nossos solos. Nazareno: Editora Eletrônica: Lua Comunicação (s/d).
} 
de uma longa história cultural. As mudanças não se dão de forma brusca e sem transformações na natureza das relações sociais, políticas, econômicas e institucionais. A história de uma cultura vai estabelecendo processos específicos de mediação com seu meio geográfico e a articulação de uma formação social com a ordem econômica dominante (LEFF, 2009). A partir desse projeto, pretende-se discutir as contradições, desafios e limites das experiências de desenvolvimento na escala local. Esse projeto representou uma referência a partir da qual outras atividades foram se desenvolvendo, sinalizando o início da redefinição não apenas da paisagem local, mas das práticas agrícolas e sociais da comunidade.

O objetivo deste trabalho é, portanto, apresentar alguns resultados do Projeto Maria de Barro, suas bases teórico-metodológicas, visando contribuir para a reflexão sobre os desafios que essas experiências apresentam para as comunidades e para os gestores públicos. Pretende-se também discutir os elos intrínsecos entre desenvolvimento, território e tecnologia. Entendemos tecnologia como um corpo específico de conhecimento, nem sempre respaldado em explicações científicas, um quantum de conhecimento retido por pessoas e organizações, portanto, profundamente imbricada com as histórias e culturas locais.

Este artigo é constituído por essa introdução, seguida de breve contextualização do projeto e apresentação de suas bases conceituais; o terceiro item apresenta o projeto Maria de Barro e as metodologias implícitas nas suas diversas atividades, bem como as diversas escalas e atores associados a essas ações; e no quarto item faz-se o esforço de reflexão sobre os resultados e os desafios na consolidação e continuidade dessa experiência.

\section{O projeto Maria de Barro: contextualizando a experiência}

O projeto Maria de Barro nasce no contexto de uma crise socioambiental, de civilização, cuja superação, segundo Dupas (2008), exige uma alteração profunda não somente nos padrões científicos e tecnológicos, mas também nos sistemas produtivos, nos valores consumistas e no uso da energia fóssil. Segundo o autor, vários problemas que atingem a biosfera e as sociedades que nela vivem, como o aquecimento global e a desertificação, entre outros, assumem dimensões tão complexas que exigem, para o seu entendimento, colaboração e diálogo entre as diversas disciplinas naturais e humanas.
Para o discurso neoliberal, a controvérsia entre crescimento e preservação do meio ambiente é uma falácia. Para estes, os mecanismos de mercado são o meio mais acertado e eficaz para internalizar as condições ecológicas e os valores ambientais ao processo de crescimento econômico. Nessa perspectiva, os problemas ecológicos não surgem como o resultado da acumulação de capital nem por falhas do mercado, mas por não se haver atribuído direitos de propriedade e preços aos bens comuns. As soluções passam assim para a ampliação da lógica de acumulação capitalista, a mercantilização da natureza e dos valores culturais e étnicos (LEFF, 2009).

Entretanto, o acirramento dos problemas ambientais e sociais nas últimas décadas tem provocado não apenas o aumento do debate sobre as orientações implícitas nos projetos de desenvolvimento, sua relação com a dimensão territorial, mas o surgimento de práticas profundamente inovadoras na perspectiva conjunta da preservação ambiental, da cidadania e participação política (BRANDÃO, 2008). O Projeto Maria de Barro se insere nessas experiências que buscaram na história e nas formas culturais os sinais e os elementos de diálogo com as condições de vida e as práticas produtivas e de sociabilidade. A partir de uma problemática-chave do município de Nazareno - a degradação dos solos percebida pela presença maciça de voçorocas - buscou-se expandir a consciência e a participação da comunidade sobre os diversos problemas que a atinge. As voçorocas são a dimensão visível de uma série de problemas e o resultado da forma como os indivíduos estabeleceram vínculos com a natureza e entre si.

As bases do projeto Maria de Barro são lançadas em 1999, com o projeto Controle e Estabilização de Voçorocas que, a partir da recuperação de uma voçoroca-piloto, permitiu construir uma tecnologia social de fácil replicação e que está sendo difundida em alguns municípios da região. Este projeto foi realizado com recursos do Fundo Nacional do Meio Ambiente. Essa tecnologia utilizou a degradação ambiental como um meio de potencializar o debate e ações para o desenvolvimento local. O Projeto Maria de Barro inicia-se em julho de 2004 com o apoio do BNDES, fruto e expressão da compreensão da complexidade dos problemas ambientais e da necessidade de se organizar a gestão e integração das diversas atividades existentes no município, na perspectiva de consolidar práticas e conhecimentos que pudessem construir alternativas de sociabilidade, produtivas, ambientais e institucionais. Essas práticas e conhecimentos envolvem hoje cerca de 30 municípios, territórios que vivenciam as mesmas problemáticas. O projeto foi orientado 
pelo diálogo entre três conceitos básicos: desenvolvimento, território e conhecimento tecnológico.

O Projeto Maria de Barro se insere no contexto dessas iniciativas "locais", que se tornaram processos de transformação ambiental e social permanente. A complexidade dos problemas e dos conflitos de interesses obrigou as partes a negociarem e a construírem novos espaços de participação e práticas em que se valorizam todos os tipos de saberes próprios do território. O projeto Maria de Barro é o resultado de uma trajetória de luta e representa apenas um momento de um processo dinâmico e que cria constantemente novos desafios. Essa experiência de transformação das condições socioambientais se inicia a partir de um problema crucial do município de Nazareno: a degradação dos solos, percebida pela presença maciça de voçorocas. Mas o projeto Maria de Barro não foi a primeira iniciativa ligada à problemática ambiental em Nazareno. As experiências anteriores foram fundamentais para a mobilização da comunidade e a integração com a escola, universidade, prefeitura e outras instituições.

A primeira ação educativa voltada para as questões ambientais implantadas em Nazareno chamou-se Projeto Escola Viva e caracterizou-se pela aproximação dos conteúdos curriculares com a realidade da comunidade. Essa reestruturação curricular, realizada no primeiro semestre de 1998, objetivou integrar os conteúdos das disciplinas biologia, geografia e educação física entre alunos e professores da rede estadual e municipal. A preocupação era que os estudantes reconhecessem o ambiente como "casa" e estabelecessem uma relação mais harmônica com o seu entorno.

O Projeto Escola Viva, entretanto, não conseguiu romper a resistência conservadora devido à falta de informações e de sensibilidade perante as questões ambientais por parte dos tomadores de decisões. As mudanças curriculares propostas ficaram reduzidas a algumas disciplinas. Assim, acabou sendo uma ação pontual e fragmentada, mas que teve o mérito de introduzir o debate sobre as questões ambientais no espaço da escola.

A segunda experiência precursora do projeto Maria de Barro foi o Projeto Cidade Limpa, iniciado em agosto de 1999 pelas escolas do município em parceria com a Companhia Energética de Minas Gerais (Cemig), que promoveu o Curso de Capacitação de Professoras em Metodologias de Educação Ambiental e disponibilizou a Estação Ambiental de Itutinga para a realização de atividades pedagógicas com os educandos. A partir daí, as escolas implantaram uma campanha para sensibilizar toda a comunidade sobre a questão do lixo no município por meio de várias atividades, como a elaboração de peças teatrais, músicas, poesias e brinquedos, além da promoção de campanhas educativas de caráter contínuo e permanente em Nazareno. Isso abriu espaço para as discussões sobre a complexidade das questões ambientais, ampliando os espaços de convivência - uma forma de estabelecer o diálogo entre a casa e a rua.

Em 1999, com recursos do Fundo Nacional do Meio Ambiente, inicia-se o projeto Controle e Estabilização de Voçorocas, que permitiu, a partir da recuperação de uma voçoroca-piloto, construir a tecnologia social que está sendo implantada atualmente em alguns municípios da região. Essa tecnologia utilizou a degradação ambiental como um meio de potencializar o desenvolvimento local através de três linhas básicas: sensibilização ambiental e redefinição da relação água/solo/sociedade; implantação da metodologia da Agenda 21 local em Nazareno; e implantação da educação ambiental formal e popular, por meio de várias atividades como: mutirões de plantio em voçorocas, coleta de sementes, produção de mudas, compostagem, passeios interpretativos de diagnósticos socioambientais, oficinas lúdicas e de ética-cidadania-direitos humanos, palestras, reuniões de organização comunitária e cursos de capacitação social. Essas atividades envolvem vários aspectos da vida e têm contribuído para mudanças de atitude das comunidades em relação às diversas formas de sociabilidade que elas estabelecem entre si e com a natureza.

Dessa experiência, em 2004 inicia-se o Projeto Maria de Barro, com o apoio do BNDES, o qual sugere a compreensão da complexidade dos problemas ambientais e da necessidade de organizar a gestão e a integração das diversas experiências e atividades numa perspectiva de consolidar práticas e conhecimentos desenvolvidos e difundi-los para os diversos territórios que vivenciam as mesmas problemáticas. O BNDES financiou também a construção do prédio da sede do Centro Regional Integrado de Desenvolvimento Sustentável (Crides), completamente projetado e desenvolvido com tecnologias ecológicas envolvendo saberes locais de construção. O Crides é responsável pela gestão do projeto e tem como objetivo desenvolver metodologias de trabalho socialmente construídas com a perspectiva de capacitar as comunidades para a consciência política e o exercício da participação como passo importante na construção de uma sociedade mais justa e responsável, respeitando a diversidade cultural e ambiental. O Projeto Maria de Barro é mais do que uma tecnologia social e pretende, por isso, estimular uma nova percepção do mundo, aquela que busca redefinir a histórica relação homem/natureza. 
Construção das bases conceituais e metodológicas

\section{O sentido do (des)envolvimento}

Entendemos que a compreensão das condições dos países e de sua posição no mundo exige um conhecimento profundo do discurso sobre o "desenvolvimento", bem como os modos como conhecemos e construímos o mundo "em (des)envolvimento" são condições para a mudança destes. Como e por que a questão do desenvolvimento passa a ser um tema recorrente e presente no discurso de várias instituições de ajuda internacional? Direcionado por essas preocupações, Rist (2001) traz uma contribuição importante ao debate sobre os interesses implícitos na ajuda para o "desenvolvimento" por parte dos países desenvolvidos e na definição dos EUA como o padrão de referência a ser perseguido. Segundo Rist (2001), o conceito de desenvolvimento é inventado em um momento pouco favorável às preocupações extraocidentais. Os termos "desenvolvimento" e "subdesenvolvimento" aparecem pela primeira vez no Ponto IV do discurso do Presidente Truman, de 1949, no qual se propõe estender às nações desfavorecidas a ajuda técnica acordada, até aquele momento, com certos países da América Latina. Pode-se dizer que esse ponto inova conceitualmente e inaugura uma nova forma de lidar com as relações internacionais. Já não se trata mais de uma relação entre metrópole/colônia, mas de uma relação entre possíveis iguais. Ao falar das nações desfavorecidas, o discurso introduz o conceito de subdesenvolvimento. A relação desenvolvidos/subdesenvolvidos incorpora a ideia de continuidade entre os dois termos, que aponta o crescimento econômico como a única forma de reduzir as diferenças entre os dois tipos de países e, quiçá, superá-las. Os constrangimentos históricos da periferia são desconsiderados e o crescimento transforma-se na única saída. A forma de medir os diferentes níveis de desenvolvimento seria o Produto Nacional Bruto - PNB, liderado na época pelos EUA. Nessa perspectiva analítica, o desenvolvimento é um conceito transcultural e de validade universal (RIBEIRO, 2009). Segundo Souza (1996), a ideia de desenvolvimento está culturalmente enraizada na modernidade, que é também uma cria da entidade histórico-geográfica chamada Ocidente e de seus valores, especialmente a razão.

Celso Furtado, em 1974, chama atenção para a transformação do desenvolvimento em um mito, algo a ser vislumbrado e sonhado por todos. Segundo o autor, a crença nele tem impedido os países da periferia de olharem para suas necessidades concretas, e são estas que orientam a compreensão crítica da realidade e o avanço da ciência. Esta, por sua vez deveria ser pensada para atender as necessidades específicas da periferia, orientar-se para a resolução de problemas inerentes a cada realidade e, consequentemente, para o avanço do conhecimento geral, que servirá de suporte também para a pesquisa aplicada. Os mitos funcionam como uma espécie de farol que orienta o campo de percepção do cientista social sobre a realidade, apontando para o que é ou não relevante para se ver, compreender e mudar. Os mitos direcionam a construção do saber. Seria então necessária a desmistificação desses saberes e a construção de outros saberes, respaldados nas necessidades concretas das experiências periféricas. Isso não significaria a negação das contribuições dos países desenvolvidos, mas a construção de um olhar crítico que pudesse dialogar com esses saberes e não se subordinar a eles.

Essa perspectiva da ciência e do conhecimento esteve por trás dos debates sobre o desenvolvimento periférico e foi também a base orientadora do pensamento crítico na América Latina a partir das contribuições da Comissão Econômica para América Latina e Caribe (Cepal). Os trabalhos aí produzidos vão mostrar a importância de se perceber o subdesenvolvimento como uma especificidade de desenvolvimento periférico e dependente, mas não uma etapa de um processo linear. Sua superação passaria por transformações de natureza estrutural e política (FURTADO, 1974). Buscou-se, com inspiração nessas contribuições, pensar o desenvolvimento local e a importância do olhar crítico para a redefinição dos laços homem-natureza e sociedade-meio ambiente.

Após um longo período de expansão, os anos 1970 foram marcados por uma grande reestruturação mundial, acirramento do processo de internacionalização das economias (entenda-se expansão dos grandes grupos transnacionais, que impõem os seus padrões de competitividade). Esse movimento mundial, multifacetado, denominado globalização, fortaleceu os grandes interesses transnacionais e acentuou os processos de exclusão social da periferia interna (grupos marginalizados nos países industrializados) e externa (grande parcela dos grupos sociais da periferia). Esse quadro, que entendemos como uma radicalização da modernidade, terminou por respaldar, nos anos 1990, o direcionamento das políticas públicas para o local e para o fortalecimento da participação da sociedade civil como solução para a crise do desenvolvimento nacional. Nessa 
perspectiva, o debate e as propostas de desenvolvimento tenderam a minimizar, ou mesmo ignorar, os constrangimentos históricos e aqueles impostos pelo contexto de globalização (OLIVEIRA, 2002). Ainda segundo este autor, o desafio do desenvolvimento local é complexo e tem uma noção polissêmica, que comporta tantas quantas sejam as dimensões em que se exerça a cidadania; qualquer tentativa de transformá-lo em um modelo paradigmático estará fadada ao fracasso.

Castoriadis $(1983 ; 1990)$ foi um dos pioneiros na crítica ao "mito do desenvolvimento", o qual considera estar imbuído do propósito de modernização capitalista, orquestrada pelas potências hegemônicas. Para o autor, pensar outros modelos de desenvolvimento passa pelo esforço de construção teórica "aberta" ao invés de definir, de forma fechada, um conceito que estabeleça princípios norteadores. Assim, o desenvolvimento deve ser visto como um simples processo de aprimoramento (gradativo ou também através de bruscas rupturas) das condições gerais do viver em sociedade, em nome de uma maior felicidade individual e coletiva, respaldado no princípio da autonomia individual e coletiva. Autonomia entendida como um princípio ético e político. Esses princípios norteadores ultrapassariam aqueles respaldados em valores ocidentais, respeitando as práticas culturais e simbólicas de todos os povos da terra. Nessa perspectiva não existiria um desenvolvimento, linear e universal, mas desenvolvimentos, como expressão de processos específicos culturais e políticos de cada organização socioespacial.

David Harvey (2010) apresenta diversos fatores associados à dinâmica capitalista e à criatividade do sistema em encontrar novos caminhos a partir de novas organizações sociais e tecnológicas. A centralidade da crise no excessivo poder do capital aponta, segundo o autor, para novas oportunidades, transformações desse modo de desenvolvimento rentista, fortemente competitivo e individualista. Harvey sinaliza a importância de se pensar a perspectiva do desenvolvimento humano, das capacidades humanas de buscar o novo. Valorizar aspectos da vida, da sociabilidade como a poesia, a música e as várias áreas das artes e humanidades. A busca pelo novo, pela realização, seria o motor da dinâmica do desenvolvimento, de um outro (grifo nosso) desenvolvimento. Esse é o pensamento utópico de Harvey. Não seriam eliminados os conflitos e os diversos problemas oriundos dos processos socioespaciais, mas a busca fundamental seria pelo "florescimento" da capacidade humana.
Assim, as primeiras discussões sobre as bases do projeto Maria de Barro fundamentam-se na compreensão da realidade de Nazareno e seu entorno como fruto de um processo de desenvolvimento colonial, sem nenhum vínculo ou preocupação com a preservação ambiental e dos saberes locais. As alternativas, mesmo que locais, precisariam dialogar com outras experiências e envolver a população, de forma crítica, como produto e produtor dessa realidade. A perspectiva da participação política e democrática é condição básica da transformação das condições socioambientais.

\section{O conhecimento e a tecnologia como produto coletivo e social}

A relação entre os domínios da ciência e da tecnologia não é simples nem linear. Muitas vezes, são as mudanças tecnológicas que alimentam a agenda de pesquisa. A relação entre ciência e tecnologia se torna mais explícita e imbricada a partir da primeira revolução industrial, no século XVIII. Antes, as oficinas poderiam ser denominadas verdadeiros centros de arte, em que os produtos expressavam saberes, experiências e habilidades. A expansão do modo capitalista de produzir exige a permanente renovação das técnicas para operar a destruição criativa. A racionalização crescente da sociedade estaria, assim, ligada à institucionalização da evolução científica e técnica.

Schumpeter (1982) foi um dos primeiros economistas a dedicar suas pesquisas à compreensão da relação entre inovação tecnológica e desenvolvimento econômico. Para $\mathrm{o}$ autor, as novas tecnologias criam e destroem as antigas, promovendo o que ele chamou de "destruição criativa", que suportaria o processo de acumulação capitalista. Como aponta Dupas (2008), a ciência teria o papel de promover permanentemente um estado de inovação, sucateamento do conhecimento, produtos e hábitos. A inovação é, assim, o processo que envolve um novo desenvolvimento, sua introdução no mercado, a sua distribuição e uso final. Pode ser de produto, processo e organizacional (LUNDVAL, 2002). Por outro lado, há inovações que apresentam baixo grau de apropriabilidade e que, por isso, não se mostram atrativas para o empreendedor privado, mas podem incorporar um grande potencial de transformação de estruturas, condutas, formas de organização locais, as quais, por sua vez, no longo prazo, tendem a viabilizar a operação de empreendimentos produtivos competitivos. 
Estudos mais recentes mostram que o aprendizado tecnológico necessita de esforço consciente, propositivo e incremental para coletar novas informações, tentar coisas novas e criar novas habilidades e rotinas operacionais, bem como estabelecer novos relacionamentos com atores externos. Depreende-se, portanto, que a capacidade de inovação deriva da confluência de fatores sociais, institucionais e culturais específicos dos ambientes em que se inserem os agentes econômicos, sociais, culturais e políticos, além dos padrões competitivos dos setores nos quais as empresas estão inseridas. Isso significa que inovar é, também, um processo social e coletivo (CALLON, 1992).

Foi a partir da perspectiva de ciência "aberta" que o projeto Maria de Barro concebeu as tecnologias. Ou seja, a partir das necessidades concretas da sociedade e das condições socioambientais e a partir da valorização do diálogo entre saberes científicos e não científicos.

A lógica do capital transformou a pesquisa tecnológica em área privada, associada aos grandes grupos de empresas transnacionais. A ciência moderna se subordinou a uma lógica e se distanciou dos interesses reais da sociedade. A atuação sobre o meio ambiente está associada à qualidade de vida da comunidade e à maneira como esta influencia as formas de intervenção sobre a realidade, na perspectiva de preservá-la e transformá-la. Segundo Leff (2001), trata-se de construir uma nova epistemologia política ou uma mudança de racionalidade que combine a questão da ética e do conhecimento para a construção de um saber que aporte luzes para a compreensão da complexidade ambiental. Como apontam Morin e Moigne (2000), deve-se reavaliar o sujeito do conhecimento em favor de outras concepções mais interativas, menos antropocêntricas e mais dialógicas, que valorizem a arte do pensar. Nessa perspectiva, o conhecimento do homem e dos seus problemas não pode ser separado do Universo, mas inserido nele. "Quem somos é inseparável de onde estamos, de onde viemos e para onde vamos" (PASCAL apud MORIN; MOIGNE, 2000, p. 25). A compreensão e atuação sobre o local e o território não se limitam ao espaço físico limitado geograficamente, mas a um espaço que tem uma história, uma cultura e identidades. A compreensão dessa trajetória é fundamental para a construção de uma consciência humanística e ética de pertencer à espécie humana, à dimensão terrestre e à dimensão local, para um agir responsável sobre essa realidade. $\mathrm{O}$ agir transformador implica a consciência e a compreensão do processo histórico. A noção de pertencimento implica o autorreconhecimento das pessoas como capazes de interagir com os outros, de ouvir e serem ouvidas, de respeitar e serem respeitadas (CENPEC, 1998, citado por SEGURA, 2001). Nesse sentido, como ressalta Segura (2001), a ampliação das relações de pertencimento depende da predisposição individual e coletiva para mudar o olhar e as atitudes. É nessa perspectiva que Sousa (1987) afirma que, à medida que se superam as dicotomias entre mente e matéria, observador e observado, subjetivo e objetivo, coletivo e individual, animal e pessoas, a distinção entre ciência natural e ciência social deixa de ter sentido.

Portanto, compreendendo-se que toda ciência é ciência social, que todo conhecimento é socialmente construído, toda tecnologia é também uma tecnologia social ${ }^{4}$. O controle da sua produção e uso é que a dissocia dos interesses maiores da sociedade. Qualquer conhecimento só o é, como autoconhecimento, como momento de reconhecimento de incompletude do saber de uma dada cultura, no momento em que se entra em contato com outra (SANTOS, 1987). Para romper a monocultura do saber, Boaventura nos propõe o conceito de Ecologia dos Saberes. Não se trata de "descredibilizar" as ciências, mas fazer o uso contra-hegemônico da ciência hegemônica. A ciência torna-se assim parte de uma ecologia mais ampla de saberes (SANTOS, 2007). Foi nesse sentido que o projeto Maria de Barro abordou a dimensão tecnológica, totalmente solidária à perspectiva socioterritorial do desenvolvimento. As tecnologias foram construídas a partir do diálogo entre agrônomos (saber científico) e os saberes e práticas locais, criando um novo saber com o envolvimento da comunidade. A recuperação das voçorocas foi planejada a partir do mapeamento histórico e ambiental do território; das principais espécies florestais, sistemas de manejo e cultivo e as práticas culturais. Os valores culturais entrelaçam com o saber acumulado numa grande experiência e tradição histórica. Assim, as técnicas usadas alcançam um alto grau de complexidade, articulando-se com elemen-

\footnotetext{
${ }^{4}$ Para alguns projetos o conceito de Tecnologia Social compreende produtos, técnicas ou metodologias reaplicáveis, desenvolvidos na interação com a comunidade e que representem efetivas soluções de transformação social. Trata-se de um conceito que remete a uma proposta inovadora de desenvolvimento, considerando a participação coletiva no processo de organização, desenvolvimento e implementação. Está baseada na disseminação de soluções para problemas voltados a demandas de alimentação, educação, energia, habitação, renda, recursos hídricos, saúde, meio ambiente, dentre outras. Disponível em: <http://www.tecnologiasocial.org.br/ bts/publicador.do?op=noticia\&codigoNoticia=1\&codigoTipoTexto=2>. Acesso em: 13/09/2010.
} 
tos da organização social e com as formações ideológicas, místicas e religiosas das comunidades envolvidas no projeto Maria de Barro. Espera-se que o diálogo entre as diversas esferas da formação da comunidade influenciem as ações políticas e econômicas, alterando as correlações de força dos interesses territoriais.

\section{Territórios, territorialidades, espaços de desenvolvimento}

Em uma análise do movimento de atuação das políticas públicas e sua inserção no movimento capitalista de acumulação, Fernandes e Cano (2005) articulam os interesses que movem as relações local/global. Segundo os autores, percebe-se um duplo movimento de redefinição das escalas de ação político-econômica: um, para "cima", de integração global da atividade econômica e da decisão política, e outro, para "baixo", de descentralização para a escala local da organização da vida cotidiana. Em vez de antagonismo entre o local e o global, nota-se uma funcionalidade entre as duas escalas. Mostrando como essa discussão é bem mais complexa do que a dualidade local/global, a dinâmica do processo de acumulação capitalista se dá nas várias escalas simultaneamente. Nesse sentido, os autores sugerem que a construção de alternativas progressistas de desenvolvimento com justiça social requer abordagens metodológicas e políticas transescalares, devendo-se, portanto, aprofundar o significado desse local.

Segundo Brandão $(2007$; 2008), as políticas de desenvolvimento com maiores e melhores resultados são aquelas que não discriminam nenhuma escala, mas reforçam as ações multiescalares microrregionais, mesorregionais, metropolitanas etc., em que as escalas espaciais são construídas ou reconstruídas (analítica e politicamente) a partir das formas mais adequadas a cada problema concreto a ser diagnosticado e enfrentado. Ou seja, nenhuma escala ou desenho de política pode ser reproduzido de maneira uniforme, desconsiderando os interesses e as capacidades de cada lugar.

A territorialização das intervenções públicas tornou-se uma panaceia para todos os problemas do desenvolvimento. "Assevera-se, de forma velada ou explícita, que todos os atores sociais, econômicos e políticos estão cada vez mais plasmados, 'diluídos' (subsumidos) em determinado recorte territorial” (BRANDÃO, 2007, p. 12). Segundo Veltz (1996), a mundialização gera processos diversos e contraditórios que não levam, necessariamente, à elimina- ção ou minimização das diferenças. Não é a unificação que predomina, mas a coalizão e a imbricação crescentes de diferentes escalas. Qualquer padrão ou escala pré-definido(a) pode mascarar ou impedir que se compreendam as dinâmicas específicas e a forma como cada espaço se defende, reage ou se integra aos processos de transformação global.

O território é fundamentalmente um espaço definido e delimitado por e a partir de relações de poder (SOUZA, 1995). Para Hissa (2002), a valorização do conceito de território emerge também da crise do saber atual, caracterizado pela discussão da ciência sobre a validade de modelos totalizantes. $\mathrm{O}$ conceito de território torna-se chave para a compreensão do lugar e da natureza da sociabilidade contemporânea.

É a geografia que tem aprofundado esse debate, principalmente a partir das contribuições de Henri Lefèbvre (1974), para quem o espaço desempenha um papel e uma função decisiva na estruturação de uma totalidade, de uma lógica, de um sistema. Outra contribuição importante foi a de Milton Santos, com a incorporação do conceito socioespacial, derivado do conceito de formação socioeconômica. Para este autor, não é possível conceber uma determinada formação socioeconômica sem se recorrer ao espaço. Modo de produção, formação socioeconômica e espaço são categorias interdependentes (SANTOS, 1978). Ressaltam-se as contribuições mais recentes de David Harvey (2006), que introduz a reflexão espaço-temporal, ressaltando a importância dos espaços construídos, além dos interesses e as dimensões simbólicas envolvidas.

O território surge, na tradicional geografia política, como o espaço concreto em si, que é apropriado por um grupo social. A ocupação de um território gera raízes e identidades. Numa perspectiva crítica, o território é visto como um campo de forças, uma teia, uma rede de relações sociais que, a partir de sua complexidade interna, define, ao mesmo tempo, um limite, uma alteridade: a diferença entre "nós" e os "outros". Territórios são relações sociais projetadas no espaço (SOUZA, 1995). Um território é uma rede de relações sociais e produtivas, capazes de produzir singularidades. Um lugar compartilhado no cotidiano e receptáculo da memória coletiva. Como ressalta Santos (1978), a categoria de análise não é o território em si, mas o território utilizado, construído, pois o espaço é sempre histórico. A compreensão da constituição socioespacial de Nazareno e seu entorno foi fundamental para o mapeamento das identidades, saberes e a identificação dos fatores subjacentes às práticas culturais, sociais e agrícolas. A partir 
dessas identidades, se expandiram a problemática e as ações nos territórios das vertentes, banhados pelo Rio Grande.

Segundo Reis (apud BRANDÃO, 2007), existem dois paradigmas que orientam o entendimento do conceito de território: o da mobilidade e o da genealogia. O primeiro considera o território como receptáculo de movimentação de fatores produtivos no espaço. Nessa perspectiva, o desenvolvimento passa a depender da performance do território, de seu acúmulo de relações e de capacidade institucional. O segundo paradigma atribui ao território um papel ativo, valoriza o caráter conflituoso por essência de uma construção histórica de desenvolvimento. A valorização ou o reconhecimento apenas de uma única escala, a local, como a melhor para o desenvolvimento, significa reduzir as dinâmicas e as forças da globalização sobre os espaços e as estruturas produtivas. A discussão da escala espacial destes processos é fundamental para a compreensão das determinações "territorializadas" dos fenômenos sociais (BRANDÃO, 2007) e para, a partir daí, desenhar as diversas formas e escalas de políticas.

O projeto Maria de Barro absorveu várias atividades, redes de conhecimento, que trabalham com escalas diversas. O resgate dos saberes da construção civil e o uso do adobe foram estimulados na própria comunidade de Nazareno, a partir de um grupo de mulheres que se responsabilizaram pela produção desses tijolos para a construção do Centro Regional Integrado de Desenvolvimento Sustentável - Crides. Um grupo de arquitetos e engenheiros desenhou o projeto do Centro, valorizando as tecnologias ecológicas, aproveitamento dos materiais da região e das condições naturais, chuvas e sol. A construção teve como base o protótipo de uma casa, com materiais que poderiam ser utilizados em habitações, para que a população conhecesse essa nova opção de moradia. O objetivo era que as novas construções das prefeituras fossem feitas empregando uma tecnologia sustentável, abrindo espaço para o desenvolvimento de uma cadeia produtiva atrelada a essa iniciativa. Os custos das construções tenderiam a abaixar com o aumento da produção e o emprego cresceria na região. Entretanto, forças e interesses políticos não permitiram a concretização dessa proposta. Mas a qualidade e a funcionalidade do Crides são uma referência para todos que visitam a região.

Já a discussão sobre práticas agrícolas envolveu todas as comunidades onde havia forte incidência de voçorocas. Naquele momento, o mais importante era a conscientização dos agricultores quanto às consequências das práticas predatórias para a sustentabilidade de sua propriedade. A dis- cussão de práticas de conservação dos solos se deu a partir da Rede Voçoroca. Essa rede foi criada com o objetivo de estimular as trocas de conhecimento entre as comunidades e teve o apoio do projeto KASSA - Knowledge Assessment and Sharing on Sustainable Agriculture, que atua em vários países. Essa experiência mostrou a importância das redes na troca de conhecimentos e na formação de laços de solidariedade entre os povos. A territorialidade assume a dimensão e a forma que os fenômenos exigem. Nessa perspectiva, o desenvolvimento delineia os traços e especificidades das culturas envolvidas. A escala de intervenção é múltipla, do local ao global.

\section{Dialogando conceitos e práticas: as ações socioambientais}

A degradação do recurso natural solo é um dos problemas mais críticos enfrentados pela humanidade. As respostas para esse tipo de problema, como se tem demonstrado, apresentam possíveis indicadores de reabilitação, mas os efeitos dessa degradação muitas vezes persistem ou se estabelecem novamente (LAHMAR et al., 2001). Nesse contexto, a equipe do projeto se depara com situações de riscos ambientais grandes e com o desenvolvimento de processos erosivos nas Bacias Hidrográficas Alto Rio Grande e Vertentes do Rio Grande, que não foram enfrentados na história passada com tanta devastação. Para lidar com esses problemas, percebeu-se a importância de compreendê-los a partir das práticas produtivas e sociais das populações afetadas. Era preciso construir um caminho de intervenção que dialogasse com as comunidades para que estas pudessem tomar consciência do seu envolvimento e do seu papel na transformação desse cenário. Nessa perspectiva, fomos guiados pelo conceito de território, espaços de poder, identidade, simbologias e sonhos, para delinear as estratégias de ação junto às comunidades.

A baixa sensibilidade à complexidade desses problemas por parte dos técnicos envolvidos em projetos de recuperação explica, em parte, os resultados pouco satisfatórios dos recursos aplicados. O alcance quantitativo dos programas convencionais de conservação do solo e da água é aparentemente impressionante. Em todo o mundo, terraços foram construídos, árvores plantadas e agricultores treinados maciçamente. Alguns desses esforços possivelmente reduziram a extensão da erosão dos solos e contribuíram para incrementar os níveis de produtividade agrícola. No 
entanto, na maior parte dos casos, esses resultados têm uma vida curta e tendem a ocorrer somente dentro dos limites do projeto durante a sua duração. As populações locais, cujas terras estão sendo tratadas, reabilitadas ou recuperadas, não participam integralmente e nem são adequadamente consultadas durante o planejamento e implementação do projeto (MAZOYER; ROULDART, 1997).

Ainda que os projetos considerem a manutenção das estruturas de engenharia construídas, elas raramente são mantidas em longo prazo. As medidas de conservação se deterioram rapidamente, exacerbando a erosão que estava supostamente reduzida. Além disso, a difusão dessas tecnologias se limita a áreas restritas dos projetos e o alto custo dos pacotes torna sua utilização em novas regiões virtualmente impossível. Quando seu desempenho é medido por longos períodos, os resultados mostram-se extraordinariamente pobres em relação aos esforços empreendidos e ao dinheiro investido (GUIJT, 1996).

Segundo Hudson (1991), o fracasso de iniciativas de conservação do solo e da água em algumas regiões pode ser atribuído aos seguintes fatos:

- falta de reforço à capacitação da comunidade para implementar e manejar as medidas de conservação do solo e da água;

- formulações excessivamente rígidas dos projetos, tornando os ajustes impossíveis;

- tecnologias inadequadas.

Os resultados negativos dessas práticas e políticas, além da perda de recursos, comprometem a credibilidade das ações ligadas à conservação. Mais grave que isso, as introduções dessas práticas destruíram as técnicas locais de manejo da terra e ignoraram as redes e grupos sociais existentes. Pode-se caracterizar esse processo como um desperdício de experiência, que nega a ecologia dos saberes e reforça a monocultura do saber (SANTOS, 2007). Como sugere Boaventura de Souza Santos, a ecologia dos saberes cria a possibilidade das experiências ausentes se tornarem presentes; ela estabelece o diálogo em todos os saberes, incluindo as práticas locais, reconhece a pluralidade de formas de conhecimento além do conhecimento científico.

O espaço privilegiado para a discussão das questões ambientais e ações do projeto Maria de Barro é a escola, devido à receptividade e potencialidade de difusão das discussões e atividades coletivas para a comunidade. Além disso, é lá onde se pode dar continuidade aos trabalhos desenvolvidos com as professoras nos projetos anteriores. A escola é, também, o espaço em que se sintetiza a crise dos paradigmas, onde se questionam as noções tradicionais e predominantes de conhecimento, de avaliação e o local que traz à tona sua própria fragilidade como instituição que cristalizou a relação entre sujeito-objeto ao distanciar o conhecimento da realidade.

O projeto Maria de Barro incorpora em sua metodologia de avaliação, além de um sistema quantitativo de acompanhamento de obras de engenharia, tais como paliçadas, terraços, bacias de captação de água e viveiro de bambu, por exemplo, outras variáveis que possam apreender diferentes dimensões da intervenção. Na perspectiva do desenvolvimento humano e cultural, a produtividade tecnológica está associada à capacidade de recuperar e melhorar as práticas tradicionais de uso dos recursos. As práticas agroecológicas implementadas são culturalmente compatíveis com a lógica dos pequenos produtores. Os processos de inovação dependem das motivações das comunidades, da capacidade de absorver conhecimentos científicos e técnicos que incrementem a produtividade de suas práticas produtivas, sem destruir suas identidades e valores culturais, dos quais depende sua vitalidade, criatividade e sua energia social como fontes de produtividade. Esses indicadores são discutidos com as comunidades, visando transformarem-se em parâmetros de gestão participativa:

- mudanças na produtividade e valorização das diferentes formas produtivas;

- conhecimento das condições de fertilidade e uso produtivo dos ecossistemas;

- mudanças na degradação dos recursos, regeneração e cultivos seletivos;

- mudança no grau de independência dos grupos e das comunidades locais;

- mudança na resiliência e na vulnerabilidade do local;

- $\quad$ difusão para locais não atingidos pelo programa;

- mudanças nos procedimentos operacionais das instituições públicas envolvidas.

Esses indicadores buscam captar a inter-relação dos processos e orientam as ações futuras e os novos estilos tecnológicos, novos critérios para avaliação social das tecnologias, numa perspectiva muito mais abrangente e complexa que a controvérsia dentro da teoria econômica neoclássica entre técnicas intensivas em capital ou trabalho (LEFF, 2009). Os objetivos das mudanças tecnológicas se associam às mudanças na qualidade de vida dos usuários $\mathrm{e}$ no estímulo das práticas de solidariedade, a partir da difusão para outras comunidades e vizinhos. 
A Pesquisa Ação Participante (PAP) é a metodologia central proposta para o planejamento, implementação e avaliação dos projetos. Refere-se ao procedimento de pesquisar, partilhar, construir visões, percepções, relações sobre questões relevantes do território em conjunto com seus vários atores sociais, buscando soluções para tais questões. É a partir da inserção das comunidades nas pesquisas que se define o caminho de intervenção e mudança (THIOLLENT, 1998).

Assim, os conhecimentos relacionados com a dimensão da degradação pelas voçorocas, origens, causas, evolução espacial e relações com os fatores geológicos e sistemas agrários constituem hoje um grande banco de dados que subsidiam vários estudos e suporte às demais comunidades que se inserem no projeto.

Destacam-se algumas atividades desenvolvidas dentro desses princípios metodológicos:

i) palestras e seminários locais; geralmente a partir da realidade local, com a coordenação de uma educadora ambiental e um gestor de rede. Essas palestras acontecem em lugares públicos, ambientes naturais degradados de visibilidade, com o intuito de incentivar o engajamento na luta pela preservação ambiental;

ii) cursos de capacitação das comunidades; visam criar consciência crítica e à transformação dos sujeitos em agentes ativos de mudança. São realizadas oficinas temáticas como ética, cidadania e direitos humanos, dinâmicas que valorizam os conhecimentos tradicionais locais, educação política, noções de gestão pública e gerenciamento dos recursos ambientais e preparação para gestão das águas;

iii) passeios interpretativos da natureza; buscam despertar e cativar no público-alvo a curiosidade, motivando-o a obter mais informações e desenvolver sua criatividade. Esses passeios visam à mudança do olhar sobre as voçorocas, de modo a associar as causas e as consequências dos processos degradantes, com efeitos sobre o cotidiano das comunidades;

iv) diagnósticos socioambientais; essa prática se realiza a partir do planejamento estratégico dos municípios e bacias hidrográficas através da definição de áreas de risco, nascentes, cursos d'água e voçorocas prioritárias para o desenvolvimento de ações de recuperação. Essas atividades acontecem de forma participativa e educativa, estimulando a reflexão sobre as práticas agrícolas e a degradação do meio. A partir da identificação e distribuição dos diferentes volumes pedológicos na paisagem, os participantes são estimulados a buscarem respostas através do entendimento entre homem, solo e a água. A partir dessas atividades, foram construídos mapas de degradação ambiental que orientam as intervenções;

v) recuperação ambiental; são visitas realizadas com estudantes, populações atingidas e profissionais da área ambiental, objetivando a capacitação no diagnóstico, planejamento e recuperação de áreas degradadas. Há uma grande carência de métodos e instrumentos para esse tipo de investigação. Hoje o projeto tem um banco de dados constituído por teses, artigos científicos e outras produções didáticas que subsidiam os trabalhos. Existem hoje seis laboratórios de recuperação de voçorocas implantados como estruturas educativas e modelos acessíveis às características culturais da agricultura familiar regional;

vi) difusão da tecnologia social; o projeto utiliza a degradação ambiental como meio de potencializar a formação de educadores ambientais, a partir do desenvolvimento de atividades socioambientais e da implantação de estruturas de demonstração de recuperação em nove municípios. A difusão dessas práticas tem sido feita para vários municípios mineiros e alguns países da Europa, África e Ásia (FERREIRA; FERREIRA, 2009).

Por ser metodologia de fácil reaplicabilidade, ela está sendo implantada em mais oito municípios da região e pode ser adaptada para outras realidades que lidam com os processos de degradação dos solos. Os fatores mais importantes na sua implementação são o interesse político, disposição para enfrentar situações e variáveis complexas e interdependentes, baseadas na corresponsabilidade e disponibilidade para captação de recursos e/ou direcionamento de recursos próprios.

A experiência adquirida no processo de negociação de conflitos socioambientais permite o suporte aos municípios que aderem ao projeto. A discussão da recuperação de uma voçoroca traz também à tona questões de saneamento básico, defesa civil de estruturas urbanas, expansão urbana, especulação imobiliária, uso e ocupação do solo, problemas 
de enchentes e a questão da existência de poucas unidades de conservação em áreas urbanas e rurais. Todas essas questões são conflitos potenciais quando interferem em interesses particulares difusos. Essas discussões atrelam a dimensão tecnológica às perspectivas de desenvolvimento territorial. A expansão dessas novas práticas e o envolvimento das comunidades favorece a emergência de conflitos de interesses entre pequenos e grandes proprietários, entre formas de uso e apropriação dos solos que também colocam em xeque o poder público e as práticas políticas das prefeituras. Esses são desafios que vão sendo vencidos, ou não, no cotidiano e a partir da conscientização política.

\section{O desenho institucional: novas teias de conhecimento e ações}

Para organizar as diversas atividades de um grupo de pessoas que se engajavam na cidade e elaborar as primeiras propostas a serem negociadas com a Prefeitura de Nazareno, foi criada uma Organização Não Governamental (ONG) denominada Instituto Voçoroca. Em setembro de 1999, as duas entidades elaboraram um projeto socioambiental a ser enquadrado, para posterior avaliação, nas linhas temáticas do Fundo Nacional do Meio Ambiente. Assim, dava-se início a uma nova forma de relacionamento do Instituto com a prefeitura, que percebe a importância de abrir o diálogo e abrigar o projeto.

Na verdade, a administração municipal de Nazareno incluiu a discussão ambiental em sua pauta a partir das propostas de implementação da Associação dos Municípios Banhados pela Represa de Camargos, que se chama Ecolago Rio Grande. Essas ações assumiram maior envergadura com os projetos de educação ambiental promovidos pelas escolas públicas em parceria com a Gerência Ambiental da Companhia Energética de Minas Gerais (Cemig). Essas experiências de diálogo com a prefeitura criaram um ambiente propício à construção do Projeto Controle e Estabilização de Voçorocas de Nazareno. O Projeto Voçoroca transformou-se em verdadeiro laboratório, seja pela sua transformação em espaço de visitações da comunidade e estudantes das universidades próximas, mas também como fonte de vários trabalhos científicos (FERREIRA, 2005a;
2008; FERREIRA, 2005b; GOULART, 2005; THIMÓTEO, 2002; TOLEDO, 2002; HORTA, 2006; PIRAT, 2006) e por sua participação em diversos fóruns relacionados à temática ambiental, nacional e internacional ${ }^{5}$. Essa integração com outras instituições e a elaboração de trabalhos acadêmicos tem fortalecido e aumentado a credibilidade do projeto e a sua difusão em outros municípios. Tais trabalhos proporcionaram, também, uma melhor compreensão das relações entre a degradação dos solos e o sistema social das comunidades urbanas e rurais de Nazareno e promoveram integração e troca de saberes entre universitários e estudantes da comunidade.

Esse diálogo entre instituições e saberes viabilizou o projeto Maria de Barro, que, em 2004, institucionalizou a tecnologia "social" de recuperação das voçorocas construída a partir das experiências desenvolvidas pelo Programa Nazareno Verde. Esse projeto é fruto de ações contínuas e da construção de espaços de negociação envolvendo os atores locais e regionais na construção de novas bases para uma possível transformação socioespacial. O que se tem buscado é a sustentabilidade em uma perspectiva cultural, de longo prazo, na qual a integração e o amadurecimento dos atores vão redesenhando práticas e arranjos organizacionais e fortalecendo as instituições locais e regionais. Atualmente, o Crides é responsável pela gestão física e financeira do projeto, além de constituir o conselho gestor do programa com a participação de integrantes dos municípios parceiros.

Outros projetos foram sendo incorporados e têm contribuído para a difusão das práticas agroecológicas e a complexificação dos elos da sustentabilidade. Entre eles são citados os seguintes: a) o projeto Tecendo a Rede Voçorocas, responsável pela difusão da tecnologia social nos demais municípios participantes do Crides e por constituir uma rede de informação, a Rede Voçorocas; b) o projeto KASSA - Knowledge Assessment and Sharing on Sustainable Agriculture, fomentado pela Comissão Europeia e coordenado pelo Centro Internacional de Cooperação em Pesquisa Agronômica para o Desenvolvimento (Cirad, França), que tem como foco o estudo e desenvolvimento de formas de se viabilizar a agricultura conservacionista em solos degradados da Bacia Alto Rio Grande. Essa parceria colaborou com recursos financeiros $(\mathrm{R} \$ 25.000,00)$ e a realização de diagnósticos, entrevistas e contatos pessoais com

\footnotetext{
${ }^{5}$ Alguns dos eventos dos quais o projeto participou: FONASC; Fórum Internacional de Desenvolvimento para os Ecossistemas de Montanhas; Rede Mutirão Agroflorestal; Alliance 21 para um Mundo Plural Responsável e Solidário - Fundação Charles Léopold Mayer; LADA - Land Degradation Assessment in Dry Lands-FAO/ONU.
} 
os agricultores sobre os problemas de erosão, compactação e o sistema de agricultura implantado na região. A partir dessa experiência foram elaborados livros e cartilhas sobre as principais questões temáticas da região, difundidos para os produtores e diversas instituições.

Pela dificuldade de viabilizar áreas públicas degradadas para serem recuperadas ambientalmente, conforme exigência do BNDES e do FNMA, a Prefeitura de Nazareno está desapropriando as áreas de voçorocas, transformando-as em parques ecológicos para lazer, educação, pesquisa científica e difusão de tecnologias conservacionistas. Assim, a partir de negociações com os proprietários dessas áreas recuperadas, a Prefeitura tem conseguido transformá-las em espaços públicos. Como a recuperação de uma área degradada melhora as condições gerais da propriedade, nota-se um crescente interesse dos proprietários pela recuperação das voçorocas em suas terras. Criou-se um processo de negociação permanente entre proprietários de terra e Prefeitura, que tende, mesmo que timidamente, a redefinir a realidade socioespacial da comunidade.

No ano de 2004, foram implantados os Comitês de Bacias Hidrográficas Alto Rio Grande e Rio das Mortes visando integrar todos os municípios ao projeto ambiental e facilitar a integração das ações regionais. Os municípios participam com a cobrança de uso da água e gestão participativa dentro da política estadual dos recursos hídricos do Estado de Minas Gerais.

Em 2009, os recursos não reembolsáveis do Projeto Águas do Alto Rio Grande, no valor de R $\$ 350$ mil, foram alocados para o Fundo de Recuperação, Proteção e Desenvolvimento Sustentável de Minas Gerais. Este visa promover a consolidação do Comitê de Bacia Hidrográfica do Alto Rio Grande, fortalecendo o processo de mobilização social pelo cadastramento participativo de usuários das águas, pela implantação de um sistema de informação geográfica e pela ampliação de uma rede de informações socioambientais como instrumento de gestão da política estadual de recursos hídricos. Esse projeto fortalece a parceria com o Instituto Mineiro de Gestão das Águas (IGAM), visando à implantação de cobrança de uso da água, o que garantirá a sustentabilidade permanente do Crides, a partir de 2011 (FERREIRA; FERREIRA, 2009).

A complexidade dos elos institucionais do projeto Maria de Barro, se por um lado fortalece sua atuação, por outro promove pontos de conflitos que sinalizam desafios envolvidos na perspectiva do desenvolvimento humano e cultural.

\section{Considerações finais}

Este artigo trouxe à discussão a experiência de um projeto de desenvolvimento local, o Projeto Maria de Barro, realizado em Nazareno, Minas Gerais, região marcada por intensa e grave presença de voçorocas na paisagem, indícios de um processo de desertificação originado pela mineração do ouro no século XVIII. A partir desse grave problema das voçorocas, da dura paisagem "natural" com que convivem os moradores dessa comunidade, iniciaram-se as ações no sentido de transformar essa realidade. O projeto Maria de Barro é a consolidação de várias outras experiências de educação ambiental realizadas no município desde o final da década de 1990. As primeiras iniciativas foram desenvolvidas pelos professores da escola pública, propondo uma reforma curricular que estimulasse o diálogo interdisciplinar e a consciência da preservação ambiental. Entre várias atividades, destaca-se a prática da coleta seletiva do lixo. Essas experiências tiveram como pano de fundo a compreensão de que a degradação ambiental era o resultado, fundamentalmente, da ação humana. Mudar essa realidade exigiria mudanças profundas na postura da comunidade com relação ao meio ambiente e, inevitavelmente, nas práticas sociais e produtivas.

Os aportes conceituais foram escolhidos e organizados a partir da compreensão do diálogo indissociável entre as trajetórias de desenvolvimento, a ocupação socioespacial, as tecnologias utilizadas e os valores sociais, ambientais, éticos e políticos das comunidades. Todo desenvolvimento socioeconômico é também um desenvolvimento socioespacial, como nos ensinou Milton Santos (1978). Essa perspectiva do conhecimento direcionou as ações do projeto Maria de Barro, apresentadas aqui, para mostrar a complexidade das ações socioambientais e a importância da educação como núcleo de todo o processo de conhecimento crítico e autoconhecimento. Assim, a escola foi e é o espaço privilegiado pelo projeto para o desenvolvimento das diversas atividades, debates e cursos, pois é ali que se constrói a visão crítica do mundo, imprescindível para a sua transformação.

Nosso objetivo foi trazer para o debate essa experiência de desenvolvimento socioambiental que completa dez anos e que tem como particularidade a integração com a sociedade como elemento ativo e responsável pela sustentabilidade do processo de transformação socioespacial, valorizando a prática do respeito e do diálogo entre saberes. 
Esse diálogo entre instituições e saberes viabilizou o projeto Maria de Barro, que, em 2004, institucionalizou a tecnologia "social" de recuperação das voçorocas, construída a partir das experiências desenvolvidas pelo Programa Nazareno Verde. Esse projeto é fruto de ações contínuas e da construção de espaços de negociação envolvendo os atores locais e regionais na construção de novas bases para uma possível transformação socioespacial. Tal ação tem buscado a sustentabilidade em uma perspectiva cultural, de longo prazo, na qual a integração e o amadurecimento dos atores vão redesenhando práticas e arranjos organizacionais e fortalecendo as instituições locais e regionais.

O projeto Maria de Barro foi responsável pela construção do Centro Regional Integrado de Desenvolvimento Sustentável - Crides -, que garante a gestão física e financeira do projeto, além de constituir o conselho gestor do programa com a participação de integrantes dos 28 municípios parceiros. A construção do Crides foi realizada a partir do resgate e da adaptação científica de técnicas tradicionais e construções civis simples que estejam em conformidade com o patrimônio histórico, cultural e artístico da região. Hoje é um espaço privilegiado de realização de pesquisa, potencializando a gestão participativa do planejamento do uso e ocupação do solo do território.

Um dos grandes desafios para vários municípios e organizações do terceiro setor está no cumprimento da lei de uso e ocupação do solo, principalmente em áreas críticas de susceptibilidade à erosão, no que se refere a comunidades sob risco social e agricultura familiar descapitalizada. A criação de espaços de trocas de experiências e intercâmbios de projetos no âmbito regional e nacional, de modo que esses possam ser reaplicados em outras regiões, tem se mostrado condição fundamental para fortalecer a rede de conhecimento e reduzir o desperdício de saberes.

Apesar dos resultados positivos do projeto e dos avanços organizacionais e institucionais, há ainda muito a avançar em relação à consciência política e participativa da sociedade. Várias experiências sinalizam ser esse o fator mais importante e mais vulnerável. Não se muda uma cultura secular em alguns anos, mas esses movimentos apontam para possibilidades transformadoras. Esses desafios obrigaram o projeto a se capacitar melhor para a compreensão dos interesses envolvidos e os suportes legais para a negociação. Os conflitos são inerentes ao território e, à medida que afloram, podem ser potencializadores de mudanças. $\mathrm{O}$ ponto inovador do projeto é transformar a recuperação de áreas degradadas em uma perspectiva educacional, técnica, jurídica, política, cultural, social e econômica.

A perspectiva metodológica do projeto aflora um dos seus pontos críticos, que diz respeito à sua equipe de trabalho. Os profissionais de nível superior incorporam a dicotomia dos saberes em sua formação. Devido a essas dificuldades, o projeto construiu e treinou equipes formadas por técnicos e voluntários das comunidades - que realizam os trabalhos de difusão da tecnologia de recuperação de voçorocas e várias outras atividades educativas. Há ainda uma grande distância entre as pesquisas realizadas nas Universidades da região e as necessidades socioambientais das comunidades. Talvez aqui esteja um dos desafios para o avanço e sustentabilidade desse projeto e de todas as ações que ele potencializou: aprimorar o ensino básico e de segundo grau, aproximar a universidade da sociedade e construir o verdadeiro diálogo entre saberes, científicos ou não, mas saberes sociais, como diria Boaventura de Sousa Santos.

As voçorocas são a dimensão visível de uma série de problemas e o resultado da forma como os indivíduos estabeleceram vínculos com a natureza e entre si. Foi partindo dessa concepção que o projeto Maria de Barro construiu suas tecnologias de recuperação das voçorocas e ações que estimulassem a consciência socioambiental e a redefinição das relações floresta/solo/água/sociedade. O diálogo permanente entre instituições e saberes e a valorização da participação política das comunidades contribuem para fortalecer as dinâmicas socioambientais sobre os espaços e as estruturas produtivas, permitindo a construção de caminhos diversos de desenvolvimento, ou novos desenvolvimentos. 


\section{Referências}

BRANDÃO, C. Territórios com classes sociais, conflitos, decisão e poder. In: ORTEGA, A; ALMEIDA, F. (Orgs.). Desenvolvimento territorial: segurança alimentar e economia solidária. Campinas: Alínea, 2007.

Pacto sem territórios: escalas de abordagem e ações pelo desenvolvimento. O\&S-Especial Poder Local, n. 45, v. 15, p. 145-158, 2008.

CALLON, M. The Dynamics of Techno-Economic Networks. In: COOMBS, R.; SAVIOTTI, P.; WASH, V. Technological Changes and Company Strategies: Economical and Sociological Pespectives. Londres: Harcout Brace Javanovich Publishers, 1992.

CASTORIADIS, C. Introdução: socialismo e sociedade autônoma. In: CASTORIADIS, C. Socialismos ou barbárie. O conteúdo do Socialismo. São Paulo: Brasiliense, 1983.

Pouvoir, politique, autonomie. In: CASTORIADIS, C. Le monde morcelé. Les carrefours du labyrinthe III. Paris: Seuil, 1990.

DAGNINO, E.; OLVERA, A.; PANFICHI, A. Para uma leitura da disputa pela construção democrática na América Latina. In: ; __ _ . A disputa pela construção democrática na América Latina. São Paulo: Paz e Terra; Campinas: Unicamp, 2006.

DUPAS. G. O impasse ambiental e a lógica do capital. In: DUPAS, G. (Org.). Meio ambiente e crescimento econômico: tensões estruturais. São Paulo: Edusp, 2008. 298 p.

FERNANDES A. C.; CANO, W. O movimento do pêndulo justiça social e escalas espaciais no capitalismo contemporâneo In: CAMPOLINA, C.; LEMOS, M. B. (Org.). Economia e território. Belo Horizonte: Editora UFMG, 2005. 578 p.

FERREIRA, R. R. M. Atributos físicos e socioeconômicos em Cambissolo sob sistema de pastagem extensiva em $\mathrm{Na}$ zareno, $M G$. Dissertação (Mestrado em Manejo Sustentável do Solo) - Universidade Estadual de Londrina, Londrina, PR. 141 p. 2005a.

- Qualidade fisica de Cambissolos sobre dois materiais de origem com pastagens extensivas em Nazareno, $M G$. Tese (Doutorado) - Universidade Estadual de Londrina, Londrina, PR. 105 p. 2008.

FERREIRA, V. M. Voçorocas no município de Nazareno, $M G$ : origem, uso da terra e atributos do solo. Dissertação (Mestrado em Conservação dos Solos e da Água) - Universidade Federal de Lavras, Lavras, MG. 81 p. 2005 b.

; FERREIRA, R. R. M. Maria de Barro tecendo a Rede Voçoroca. Nazareno: Centro Regional Integrado de Desenvolvimento Sustentável, 2009.

FURTADO, C. O mito do desenvolvimento econômico. Rio de Janeiro: Paz e Terra, 1974.

GOULART, R. M. Atributos do solo e comportamento de espécies florestais em processo de estabilização de voçorocas. Dissertação (Mestrado em Ciências Florestais) - Universidade Federal de Lavras, MG. 91 p. 2005.

GUIJT, I. Avaliando o impacto do desenvolvimento participativo em microbacias hidrográficas. Alternativas - Caderno de Agroecologia - Solos, n. 4, p. 57-63, 1996.

HARVEY, D. O "novo" imperialismo: acumulação por expoliação. In: PANITCH, L.; COLIN, L. (Eds.). O novo desafio imperial. Buenos Aires: CLACSO, p. 95-125, 2006.

Pensador marxista inglês fala sobre os rumos da economia mundial (Entrevista com Elizabeth Carvalho). Globo News - programas Milênio. Recuperado em 15 de abril de 2010 de $<$ http://globonews.globo.com/Jornalismo/ GN/0,MUL1567340-17665-314,00.html>.

HISSA, C. E. V. A mobilidade das fronteiras: inserções da geografia na crise da modernidade. Belo Horizonte: UFMG, 2002. $316 \mathrm{p}$

HOLANDA, S. B. de. Raizes do Brasil. São Paulo: Companhia das Letras, 1995. $220 \mathrm{p}$.

HORTA, I. de M. F. Levantamento dos solos e ocupação da superficie do municipio de Nazareno, MG. Dissertação (Mestrado) - Universidade Federal de Lavras, MG. 74 p. 2006.

HUDSON, N. A study of the reasons for success or failure of soil conservation projects. Roma: FAO, 1991.

LAHMAR, R.; DOSSO, M.; RUELLAN, A. Cahier des Propositions du Programme Mobilisateur Sols. Paris: Charles Leopold Mayer, 2001.

LEFÈBVRE, H. La production de l'espace. Paris: Anthropos, 1974.

LEFF, E. Epistemologia ambiental. Rio de Janeiro: Record, 2001. 
Ecologia, capital e cultura: a territorialização da racionalidade ambiental. Petropólis: Vozes, 2009.

LUNDVAL, B.-A. Innovation, Growth and Social Cohesion: the Danish Model. Chetenham, Uk: Edward Elgar, 2002. 219 p.

MAZOYER, M.; ROULDART, L. Historie des agricultures $d u$ monde: du Néolithique à la crise contemporaine. Paris: Éditions du Seuil, 1997.

MORIN, E.; MOIGNE, J. L. A inteligência da complexidade. São Paulo: Peirópolis, 2000, 263 p.

OLIVEIRA, F. Aproximação ao enigma: que quer dizer desenvolvimento local? In: CASSIA-BAVA, V. P.; SPINK, P. (Orgs.). Novos contornos da gestão local: conceitos em construção. São Paulo: Polis, Programa Gestão Pública e Cidadania/FGV-EAESP, 2002. 336p.

PAULA, J. A. Raizes da modernidade de Minas Gerais. Belo Horizonte: Autêntica, 2000.

PIRAT, M. Da corrida do ouro até o êxodo rural. Qual é o futuro das atividades agrícolas numa região de forte degradação do solo? Monografia - Centre National d'Études Agronomiques des Régions Chaudes da Universidade Agropolis, Montpellier, França. 131 p. 2006.

RIBEIRO, M. T.; LOIOLA, E. Gestão do territorio e desenvolvimento: um convite à reflexão e ao exercício do diálogo entre saberes In: RIBEIRO, M. T.; MILANI, C. (Org.). Compreendendo a complexidade socioespacial contemporânea: o território como categoria de diálogo interdisciplinar. Salvador: EDUFBA, 2009. 305 p.

RIST, G. Le developpement: histoire d'une croyance occidentale. Paris: Presses de Science Po., 2001.

SANTOS, B. de S. Um discurso sobre as ciências. Porto: Afrontamento, 1987.
Renovar a teoria crítica e reiventar a emancipação social. Trad. de Mouzar Benedito. São Paulo: Boitempo, 2007.

SANTOS, M. Por uma geografia nova, da crítica da geografia à geografia crítica. São Paulo: Hucitec, 1978.

SCHUMPETER, J. A teoria do desenvolvimento econômico. São Paulo: Abril Cultural, 1982. 168 p.

SEGURA, D. S. B. Educação ambiental na escola pública: da curiosidade ingênua à consciência crítica. São Paulo: Annablume/Faesp, 2001.

SOUZA, M. L. O território: sobre espaço e poder, autonomia e desenvolvimento. In: CASTRO, I. E.; GOMES, P. C. C.; CORREA, R. L. (Orgs.). Geografia: conceitos e temas. Rio de Janeiro: Bertrand Brasil, 1995. 353 p.

. A teorização sobre o desenvolvimento em uma época de fadiga teórica, ou: sobre a necessidade de uma "teoria aberta" do desenvolvimento. Revista Território, v. 1, n. 1, p. 5-22, 1996.

THIMÓTEO, F. E. P. Programa Nazareno Verde. In: BARBOZA, H. B.; SPINK, P. (Org.). 20 experiências de gestão pública e cidadania - Ciclo de Premiação 2001. São Paulo: Programa Gestão Pública e Cidadania, FGVSP, 2002.

THIOLLENT, M. Metodologia da pesquisação. São Paulo: Cortez, 1998

TOLEDO, C. L. B. Evolução geológica das rochas máficas e ultramáficas no greenstone belt Barbacena, Região de Nazareno, $M G$. Tese (Doutorado em Geociências) - Universidade Estadual de Campinas, Campinas, SP. 308 p. 2002.

VELTZ, P. Mondialisation, villes et territoires. L'économie d'archipel. Paris: PUF, 1996.

Recebido em junho de 2010.

Aceito em setembro de 2010. Publicado em dezembro de 2010. 